\title{
Visioneering and the Role of Active Engagement and Assessment
}

\author{
Laura Yenisa Cabrera Trujillo
}

Received: 7 May 2014 / Accepted: 12 June 2014 /Published online: 25 June 2014

(C) Springer Science+Business Media Dordrecht 2014

\begin{abstract}
According to some technology enthusiasts our technological developments appear to be accelerating at an exponential rate. A common vision of such enthusiasts is that the accelerating pace of science and technology development will enable us to transform the world in more profound and significant ways than at any other time in our history. More importantly, some of these technology enthusiasts have gone beyond having technological-driven visions about the future to be actively engaged in a diverse set of activities aimed at shaping the future they envision. These are not just people with visions about the future, they are visioneers.
\end{abstract}

Keywords Public engagement - Visionner.

Visioneering $\cdot$ Vision assessment

"The best way to predict the future is to invent it" Alan Kay

According to some technology enthusiasts, our technological developments appear to be accelerating at an exponential rate [1]. One common vision of such enthusiasts is that the accelerating pace of scientific and technological development will enable us to transform

L. Y. Cabrera Trujillo $(\bowtie)$

Institute of Biomedical Ethics, University of Basel,

Bernoullistrasse 28, 4056 Basel, Switzerland

e-mail: laura.cabrera@singularityu.org the world in more profound and significant ways than at any other time in our history. More importantly, some of them have gone beyond mere technology-driven visions about the future and are actively engaged in a diverse set of activities aimed at shaping the future they envision. These are not just people with visions about the future, they are visioneers.

Patrick McCray, a historian at the University of California Santa Barbara, proposed the term 'visioneer' to refer to someone who undertakes a diverse set of futuredirected activities based on their technological visions about the future [2]. Others have used the term to refer to those whose life's work is focused on making their dreams or visions about the world a reality. Regardless of which definition we adopt, it can be said that this neologism encompasses two main concepts: that of the "visionary" on the one hand and that of the "engineer" on the other. The two of them combined embody the hybrid nature of visioneers, i.e. individuals or groups of individuals who actively engineer a clear vision they have about the future [3]. The visionary aspect is central, as it sets out a clear vision of a society as a whole that could be altered, shaped and improved by technologies the visioneers see as necessary and even inevitable. The engineering element is at least as critical, as it involves the skilful direction and creative application of scientific and technological principles to the development of novel processes, structures or equipment. Furthermore, visioneers engage in a different form of engineering when they build communities of supporters and patrons.

At its core, visioneering entails "developing a broad and comprehensive vision for how the future might be 
radically changed by technology, doing research to advance this vision, and promoting one's ideas to the public and policy makers in the hopes of generating attention and perhaps even realization" [2, p. 13]. While visions are important, especially since they add meaning to people's lives, fostering passion, motivation, direction and purpose, visioneering is more than just having a vision. It is about having conviction and determination, about taking action and bringing this action to its conclusion. Thus visioneering is different from visioning, as it enables ideas and convictions to acquire substance.

In pursuing visions, visioneers can discover and effectively respond "to new challenges, goals and opportunities, while simultaneously making new and effective responses to old problems or challenges" $[2,4]$. Visioneers can challenge long-held assumptions about what is possible and what is not. Most visions promoted by visioneers can indeed be described as being on the cusp between the possible and the impossible; in some cases this is because the technology applications they propose are too radical, though it may also be the case that the social changes they desire are unlikely to be achieved. ${ }^{1}$ Thus one can say that visioneers work at the blurred boundary between scientific fact, technological possibility and optimistic speculation, which often leads to their claims being contested and challenged by others. Moreover, given the fact that we simply cannot know in many cases what type of societal changes we would be confronted with or what the real impact of these visions would be (were they to succeed), it is then not difficult to see why some people might feel uncomfortable about visioneering projects.

Gerard O'Neill with his space colonies and Eric Drexler with his universal assemblers have both been mentioned as obvious examples of visioneers. Today, two current individuals who fit this type of visioneer description are Raymond Kurzweil and Peter Diamandis. The former is an inventor, futurist, author and the current director of engineering at Google, while the latter is an engineer and entrepreneur best known as the founder and chairman of the XPRIZE foundation. Kurzweil and Diamandis not only share positive technological visions about the future - the visionary aspect that is an essential part of the visioneering motivationbut are also actively engaged in shaping the future they envision - the engineering aspect. One example of

\footnotetext{
${ }^{1}$ This is also often said of science fiction, especially when it is too radical or if the required societal changes are too huge.
}

Kurzweil's and Diamandis's visioneer nature is their co-founding in 2008 of Singularity University, a new brand of university whose mission is "to educate, inspire and empower leaders to apply exponential technologies to address humanity's grand challenges". ${ }^{2}$ It is not only a university in which the visions supported by them and their followers are taught; it is also a place that fosters the use and development of technologies (such as nanotechnology, biotechnology and artificial intelligence) to positively shape the future. With Google as its founding corporate sponsor and with a lease agreement with the NASA Ames Research Center to house its facilities, Singularity University is committed to shaping and supporting the next generation of visioneers. One example of this is Singularity University's Graduate Studies Program (GSP), an intensive 10-week interdisciplinary and international programme whose purpose is to educate and inform the next generation of leaders about present and future opportunities. They are also trained to exploit these opportunities and deal with the disruptions resulting from exponentially growing technologies, thereby enabling them to address the grand challenges of our time. To be considered for this programme, candidates from around the world not only have to be among the most passionate in terms of their visions of a different future; they also need to have a proven track record of leadership, since both characteristics are essential in a visioneer. It is therefore clear that Singularity University is looking to produce the next generation of visioneers. In addition, the different types of activities promoted and undertaken by Singularity University are examples of visioneering, as they guide their students "toward expansive scenarios of the technological future they imagine" [2, p. 152].

Another example of an activity that reflects the nature of visioneering comes from the XPRIZE Foundation. An XPRIZE is a substantial monetary award given to the first team to achieve a specific goal set by the XPRIZE Foundation. One of the main features of an XPRIZE is a clear focus on positively impacting humanity. Interestingly, one of the paths used for prize development is called XPRIZE visioneering. ${ }^{3}$ This is an event in which thought leaders and innovators from around the world ${ }^{4}$ gather together for a weekend,

\footnotetext{
$\overline{2}$ http://singularityu.org/

${ }^{3} \mathrm{http} / / /$ www.xprize.org/prize-development

${ }^{4}$ Among the attendees are the greatest engineers, scientists and thinkers in the world, a number of entertainment industry celebrities and the senior executives of various companies.
} 
discuss the problems associated with the 'grand challenges' of today's world, and develop prize concepts for teams around the world to address these Grand Challenge areas - such as education, energy and the environment-with the hope that theirs would become the next XPRIZE to be launched. ${ }^{5}$ Several prize concepts are developed during this visioneering weekend, the prize concepts then being winnowed down to a few finalists in competition style. Last year's finalists, for example, included a prize concept for a non-invasive, affordable brain health monitor and a portable, affordable desalination device powered by wave and tidal energy.

Even though the trustees of the XPRIZE visioneering event are called "visioneers", one might question whether they truly fulfil all the attributes of genuine visioneers given that they themselves do not bring the adopted visions to completion. However, if we see visioneering as an activity that does not always have to be left to just a few groups of individuals and regard it rather as a social and community enterprise, we could indeed describe these individuals as visioneers. In this regard, as Quincy Jones remarked after attending one of the XPRIZE visioneering events, "[visioneering] is a process that can lead to the breakthroughs we need to solve the demanding issues of our world, informed by the compass of art and culture" [5]. Although this seems to be a slightly different understanding of visioneering, it nonetheless highlights a new framework for expanding and re-conceptualizing the role of visioneering, a point to which I will return below.

Another important point to consider is that in both of these examples - the Singularity University and the XPRIZE visioneering event - the visions that are being engineered are focused on bringing a positive outcome for humanity. If the focus is humanity, however, one might ask who is taking part in the debate. While there is presumably a wide variety of backgrounds ${ }^{6}$ and visions in both of these examples, it can be argued that it is still a highly selective group of people that is deciding what challenges are to be prioritized and how they are to be

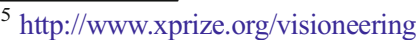

${ }^{6}$ Neither of the two cases mentioned, Singularity University or XPRIZE visioneering, requires one to be a top university scientist, corporate engineer or the like. Moreover, they gather people from different age groups and nationalities. While these forms of promoting visioneering and visioneers can thus serve as a good starting point, it is important to keep in mind that participants in these two events do have certain profiles that are by no means representative of the general public.
}

tackled. With this in mind, we should take into account the conflicts inherent in the two examples mentioned above. On the one hand, we have numerous radical visions of a technological future that is yet to be achieved, as opposed to the perhaps less radical technological development that is needed and already able to positively impact the majority of people's lives. On the other hand, precisely those people who are supposed to benefit from the projects of the visioneers are in many instances left out of the visioning and engineering of these visions of the future. ${ }^{7}$

Furthermore, the future is a contested arena characterized by diverse interests and values given that such disagreement over what the future should look like and how it might best be realized is highly likely. Specifically, visions of radical technological futures have elicited ambivalence between apprehensions of catastrophes and expectations of salvation, as well as having promoted extremely far-reaching promises and fears. Visioneering is not only about radical technological futures, however, despite this having been the main focus so far. It may concern new forms of institutions or social manifestations, ${ }^{8}$ one obvious example of this being the use of visioneering as an essential framework within sustainability sciences [3]. If visioneering includes the engineering of a vision, and engineering encompasses the application of scientific, economic, social and practical knowledge in order to design, build, maintain and improve structures, machines, devices, systems, materials and processes, then there are various ways in which we can have visioneering projects that are not driven by technology.

Alfred Nordmann, for example, states that visioneers need not only be rare and eccentric individuals like Eric Drexler or Raymond Kurzweil, nor need they be top scientists and engineers: "visioneering can also be viewed as a widespread collective activity" [7, p. 89]. Visioneering should be an activity pursued by an even broader community, including academics in the humanities and social sciences and the "man in the street",

\footnotetext{
${ }^{7}$ While I acknowledge that a number of social and political movements may already exist, as well as other fields involved in visioneering, these are still driven by a very select group of individuals, as in the examples of SU and the XPRIZE visioneering event. Thus my aim here is merely to emphasize the need to continue creating scope for visioneering in many more areas and spheres of society.

${ }^{8}$ We could perhaps expand the general understanding of technology to one that includes social institutions, methods and institutionalized habits of thought (cf. [6]).
} 
actively engaged in (1) producing visions that are more inclusive of other realities faced by humankind as a whole and do not necessarily constitute techno-utopian futures, and (2) in "engineering" the future, an activity that need not involve molecular machines or immortal avatars. Having said that, we already have examples of visioneering that is not driven by technology enthusiasts. For instance, it can be argued that some ethicists, social scientists, animal rights activists, environmentalists, religious groups and citizen groups have already done work that has had a substantial impact on decisionmaking. Thus their engineering does not involve technology in the narrow sense in which the term is generally understood; nonetheless, they engineer tools or processes aimed at controlling certain uses of technology, for instance stem cell or environmental technologies. ${ }^{9}$

Other community of visioneers may indeed lack the tools and knowledge, strictly speaking, to engineer technological visions of the world, but they can present different visions, challenge current ones and question and scrutinize those of others. In democratic societies different voices and different visions are needed.

More importantly, if we wish to move visioneering outside the individualistic framework in which it is generally conceived, ${ }^{10}$ we need to work even harder at envisioning how the world works and how we, as members of society, want it to be. While this distinction between an individualistic techno-utopian visioneering versus a more democratic collective visioneering can be regarded as simplistic, my intention in suggesting such a distinction is mainly to offer a starting point for discussing different possible ways to engage in

\footnotetext{
${ }^{9}$ I would like to raise the question here of whether national and international research, development and innovation programmes and funding schemes, inasmuch as they are mostly focused on addressing national/global societal challenges and have an impact on regulatory frameworks and public perception with regard to technology acceptance, are or should be considered as a form of visioneering project. My tentative answer is that they could. However, I believe it is important to acknowledge the processes and motives underlying these programmes and schemes (such as how much the general public and society as a whole are involved and how often outcomes are driven by political interests). Although I do not have a final answer to this, I would nonetheless like to leave this point open in order to maintain a discussion of these important issues.

${ }^{10}$ I use the term individualistic framework here to refer to the idea that visioneering projects take into consideration only the visions of an individual (or very select group of individuals).
}

visioneering and to be a visioneer, rather than to offer a comprehensive and definitive distinction. ${ }^{11}$

We all have a stake in this debate given that the future concerns all of us. How the future might look thus depends to a large extent on the values, technologies and institutions we choose or create, enable or disable. In this regard, visioneering as a collective activity not only allows us to defend the democratic ideal that allows the growth and diversification of today's technological ecosystems $^{12}$; more importantly, it creates scope for imagining alternative trajectories of technological and non-technological development, for "thinking and societal debate, in bringing up new questions, as well as in trying to answer them" [8, p. 382].

Visioneering on a more collective basis is crucial because visioneering, if left only in the hands of a few individuals and not involving the active reflection and engagement of the general public, can lead to unwanted futures. Transparency with respect to the different visions pursued and to the arguments, premises and conceptions behind them is indispensable for sustainable and responsible visioneering. It is also important to work towards shared visions that serve as a gateway to a responsible and sustainable communal future rather than pursuing visions that are the result or whim of one particular individual or group of individuals. This approach can potentially enable us to go beyond pursuing individual success to achieving purposes and visions of communal significance. That is why visioneering "calls for diverse functional groups in our communities to join in the processes of collaborative learning and action with stewardship" [3, p. 250]. Examples of this are the open source movement, which has built novel technologies in more democratic and inclusive ways than those developed by industry, and the transition town movement

\footnotetext{
${ }^{11}$ Moreover, while some could argue that techno-utopian visioneering generally constitutes merely the individual manifestations of social processes, the important thing to note here is that a more collective visioneering would be predominantly a social rather than an individualistic enterprise even if both are underlain by a social process. In addition, while I acknowledge that more collective visioneering can be done in an inclusive manner, it is not an inherent feature of it, nor should it imply that it would not lead to narrow visions.

${ }^{12} \mathrm{My}$ contention here is merely to stress that the dominant visioneering discourse is not sufficiently democratic as yet, not that there are no visioneering examples that are sufficiently democratic.
} 
which has focused on rebuilding towns and cities in light of climate change. ${ }^{13}$

Being a visioneer-regardless of which type we might mean - entails a high degree of social responsibility, as visioneers play an important role in social change, first and foremost because their visions are likely to give rise not only to enthusiasm but also to anxiety, and may well lead to the radical transformation of existing social arrangements, values and traditional structures. ${ }^{14}$ Furthermore, visioneers have an extended social responsibility, inasmuch as "visions have influence on the sciences' agenda", influencing - directly or indirectly - societal attitudes, perceptions and funding policies, "irrespective of their degree of plausibility, feasibility and speculativity" [9, p. 23]. If we take this seriously, we can then see, as members of society, that we have a social responsibility to actively engage in visioneering as well as to question and challenge other visioneering projects. Furthermore, if we want visions to be sustainable and ethical, visioneering will also need governance, management and monitoring [3].

Some scholars have called for vision and visioneering assessment [7-9]. The former considers the peculiar qualities of visions and questions their plausibility [10], while the latter "looks at the engineering process that has produced a compelling vision of a technological future" [7, p. 93]. In this regard, visioneering assessment not only deals with the peculiar qualities of visions or their scientific plausibility, but also with implicit conceptions of the good life, with desirability and acceptability, including a broader perspective concerning our common future and social development $[8,11]$. Thus visioneering assessment calls for a more in-depth analysis of who builds visions and why they are successful. Just like vision assessment, this would also entail an assessment of the values, attitudes, motives, perceptions, interests and worldviews driving these visions as well as those they promote [8,11], and an assessment of the methods utilized to achieve the particular vision in question [11]. Thus a comprehensive assessment would include the social, ethical, cultural,

\footnotetext{
${ }^{13}$ I thank one of my reviewers for this insight.

${ }^{14}$ I am not suggesting here that only techno-enthusiast visioneers have an impact on policy, discourse and technological paths, as there are examples of more societal visioneering approaches that have had tremendous impact on society. While it is true that the main assumption is that techno-utopian visioneers may create greater impact than other types of visioneers, there is no empirical evidence to suggest that this is necessarily the case.
}

economic and political implications and assumptions of such visions and the mechanisms of their engineering $[7,11]$. More importantly, visioneering assessment has the potential to create a deliberative space in which "to raise and debate questions about the emergence of visionary narratives and the marginalisation of alternatives when it comes to assessing the societal promise of science and technology" [12, p. 15], particularly in the context of the applications that visioneers promote.

Taking all these different points into consideration, it is clear why we need to engage more actively in visioneering, either as an active visioneer and/or by proactively assessing and deliberating on visioneering projects.

\section{Conclusion}

Visioneers from different backgrounds and with different sets of assumptions, be they individuals or groups of individuals, are crucial for the growth and diversification of today's ecosystems and for the achievement of a more meaningful and inclusive debate about the future. A visioneering approach that leaves its individualistic heritage behind to adopt a more community- and socially-oriented path would not only allow shared visions to be created; it would also permit visions and alternatives to be analysed and the possible methods of implementation to be discussed. In terms of having a broader set of shared visions, this is likely to create a valuable and more ecologically valid space in which, as members of society, we could mobilize, explore and push the limits of the possible in both the technological and social realm. In terms of vision assessment, it can be said that we all have a social responsibility to engage more actively in shaping the future. It would be beneficial if more people were to involve themselves in discussions about visioneering and in assessing and engineering visions that have been neglected but that are equally important (if not more so) on the path to positively impacting the world. This could provide a glimpse into a vast new world of technological and non-technological possibilities, while at the same time stimulating a broader discussion of the goals and visions we want to achieve as a society. If as members of society we fail to be more actively engaged in shaping the future, the consequence will be a future driven by a very narrow set of visions together with the values, technologies and interests of those involved in engineering 
those particular visions. It remains to be seen what conditions are needed for citizens to provide meaningful input to the assessment or to the pursuit of different visioneering projects, and to help us better understand who has access to political and social agenda-setting and what has prevented people from becoming "visioneers" in the more active sense of the word.

Acknowledgments I kindly thank Mike Van der Loos and Kieran Donaghue, as well as the reviewer's comments, which have helped to improve this manuscript.

\section{References}

1. Kurzweil R (2005) The Singularity Is Near. Penguin

2. McCray WP (2012) The Visioneers: How a Group of Elite Scientists Pursued Space Colonies, Nanotechnologies, and a Limitless Future. Princeton University Press
3. Kim J, Oki T (2011) Visioneering: an essential framework in sustainability science. Sustain Sci 6(2):247-251

4. Parnes SJ (2011) Visioneering - state of the Art. J Creat Behav 21(4):283-299

5. Jones Q (2014) Jam sessions for Global Progress. Huffington Post. Available at: www.huffingtonpost.com/x-prizefoundation/quincy-jones-artists-do-i_b_3417895.html

6. Jasanoff S (2003) Technologies of humility: citizen participation in governing science. Minerva 41:223-244

7. Nordmann A (2013) Visioneering assessment: on the construction of tunnel visions for technovisionary research and policy. Sci Technol Innov Stud 9(2):89-94

8. Grunwald A (2007) Converging technologies: visions, increased contingencies of the conditio Humana, and search for orientation. Futures 39(4):380-392

9. Grunwald A (2013) Techno-visionary sciences. Challenges to policy advice. Sci Technol Innov Stud 9(2):21-38

10. Grin J, Uhl DMA, Grunwald A (2011) Vision Assessment: Shaping Technology in 21st Century Society. Springer Verlag

11. Ferrari A, Coenen C, Grunwald A (2012) Visions and ethics in current discourse on human enhancement. NanoEthics 6:215-229

12. Coenen C, Simakova E (2013) Governance of visionary technosciences. Sci Technol Innov Stud 9(2):3-20 